\title{
Adaptive foraging strategy of an insular snake (Lycodon semicarinatus, Colubridae) feeding on patchily distributed nests of sea turtles
}

\author{
Kazumasa Matsumoto* and Akira Mori \\ Department of Zoology, Graduate School of Science, Kyoto University, Sakyo, Kyoto \\ 606-8502, Japan \\ *Corresponding author's e-mail address: matsumoto.kazumasa.87e@st.kyoto-u.ac.jp
}

Received 2 March 2021; initial decision 19 April 2021; revised 18 May 2021;

accepted 19 May 2021; published online 2 June 2021

\begin{abstract}
Foraging tactics of predators generally include two major modes, active searching and ambushing. A colubrid snake, Lycodon semicarinatus, is a typical example of a predator, which uses both tactics to forage on sea turtles on islands of the Kerama Group in the Central Ryukyu Archipelago, Japan. To investigate factors that determine the foraging mode of this snake, we conducted a fouryear field survey on its foraging behaviour on sea turtles on another island, Okinawa Island. We found that the snake performs only active searching at our study site. Snakes visited a small area exactly above the nest of sea turtles and attempted to burrow a tunnel to feed on eggs and hatchlings in the sand. Tunnels leading from the surface of the beach to the inside of the nest were formed only by large snakes. Many other snakes used the already made tunnels to capture eggs and hatchlings in the nest. When the snakes caught a hatchling, they brought the hatchling away into the nearby bush area without swallowing it above the nest (taking-away behaviour). When snakes failed to find food on a nest, they terminated the intensive search above the nest in approximately 5 minutes irrespective of snake body size, season, and the condition of the nest. Subsequently, they left the nest and resumed extensive searching for other nests. Our findings showed that $L$. semicarinatus has a different foraging strategy depending on populations. Two environmental traits, diversity of available prey animals other than sea turtles and characteristics of sand that beaches consist of, were considered as factors that might cause the difference in the foraging strategy. The fine sand of our study site enables snakes to form a sturdy tunnel in nests. We presume that such an environment facilitates the use of active searching by the snakes to find the nest with tunnels suitable for exploitation. The taking-away behaviour may be effective to reduce excessive contact with other conspecifics under the situation that the nest with tunnels attracts many visitors. Furthermore, the observation that the snake left the nest site after a consistent duration of unprofitable searching
\end{abstract}


supports the giving-up time rule, which has been predicted by a theoretical model concerning the optimal time for predators to leave a patch.

\section{Keywords}

predation, sea turtle, subtropic island, GUT rule, sandy beach.

\section{Introduction}

Foraging behaviour is a fundamental attribute that has a major fitness component for predators. Therefore, predators have evolved foraging strategies adapted to their specific habitats and prey type. Foraging strategies of predators generally includes two major tactics, active searching and ambushing (Pianka, 1966; Regal, 1978; Huey \& Pianka, 1981). Active searchers chase prey down, whereas ambushers wait for prey to enter within their field of perception and then attack it (Pianka, 1966; Schoener, 1971; Huey \& Pianka, 1981). Predators are often considered to have a species-specific single tactics (a single foraging strategy; Perry, 1999; Verwaijen \& Van Damme, 2007), and this dichotomy is advantageous for describing and predicting complex ecological community dynamics (Schmitz, 2010). Accordingly, foraging tactics of predators have been generalized as follows: active searchers tend to find and consume a higher proportion of sedentary prey than mobile prey, whereas ambushers encounter and consume highly mobile prey (Huey \& Pianka, 1981; Vanhooydonck et al., 2007). However, the actual foraging strategy of predators is not so simple because switching of foraging tactics between active searching and ambushing depending on environmental circumstances (a mixed foraging strategy) has been reported in several animal taxa (Pietruszka, 1986; McLaughlin, 1989; Helfman, 1990). The most frequently observed factor that causes switching is prey density: predators shift from ambushing at high prey density to active searching at low prey density (Formanowicz \& Bradley, 1987; Helfman, 1990). Other factors such as prey activity, ratios of the density of different prey, and predatory threat may also influence the switching of foraging tactics (Akre \& Johnson, 1979; Johnson \& Crowley, 1980). Based on several examples, Helfman (1990) suggested that the switching of foraging tactics is not a response to a single condition.

In a natural environment, food is seldom distributed uniformly in space and tends to be spatially aggregated. For example, nests, burrows, and swarms often contain multiple edible prey items (Iwasa et al., 1981; Racey $\&$ Swift, 1985). When foraging on prey within patches, both active searching 
and ambushing predators are faced with a general question, 'what is the optimal time to leave a patch?' At least three theoretical foraging models have been devised to solve this question on decision-making (Stephens \& Krebs, 1986): (1) a number rule, 'leave after catching $N$ prey' (Gibb, 1958); (2) a time rule, 'leave after $t$ seconds passed' (Krebs, 1973); and (3) a giving-up time rule, 'leave after $g$ seconds of unsuccessful search' (Krebs et al., 1974). The performance of three rules has been investigated by using a stochastic discrete model, and it is considered that different rules do best under different conditions (Iwasa et al., 1981). In particular, the giving-up time rule (GUT rule) has been analysed to be best when the quality of patch has a high variance. Krebs et al. (1974) predicted that an optimal forager in a patch should apply the same giving-up time to all patches, even if the patches differ in quality. The GUT rule is undeniably simple and has been criticized for being unlikely that predators would actually use it (McNair, 1982; Green, 1984, 1987). Nonetheless, few studies have tested the GUT rule based on field observations.

In snakes, their limbless and elongated body has led to the evolution of unique feeding methods in capturing, subduing, and swallowing prey, but the basic foraging strategy is the same as in other animals (Mattison, 1995). In general, snakes employ either active searching or ambushing, and they are considered to rely more on the species-specific single tactics than other animals. Active searching is often found among colubrids and elapids (Shine, 1980; Mushinsky, 1987). The actively foraging snakes increase searching efforts within a limited area upon detecting the potential occurrence of nearby prey (intensive search), but if the snakes are not able to encounter prey for a while, they resume the broader ranged search (extensive search): this behavioural pattern of active searching is known as area-concentrated-search (Benhamou, 1992). On the other hand, many boas (Pope, 1975), pythons (Slip \& Shine, 1988), and vipers (Reinert et al., 1984) are ambushing predators. These snakes install themselves in places where prey is likely to come and wait for their prey to come along.

Switching of foraging tactics is relatively less common in snakes, but a few studies both in the laboratory and field have reported the occurrence of the mixed foraging strategy (Mushinsky \& Mullin, 1995; Balent \& Andreadis, 1998; Mori et al., 1999; Bilcke et al., 2006; Aubret et al., 2015; Horesh et al., 2017). In an amphibious snake, Natrix maura, it has been demonstrated that switching of foraging tactics is associated with prey 
density (Bilcke et al., 2006) and water temperature (Aubret et al., 2015). In an insular colubrid snake, Lycodon semicarinatus, it has been reported that the snake alternately uses the two foraging tactics when foraging on eggs and hatchlings of sea turtles on sandy beaches on islands of the Kerama Group in the Central Ryukyu Archipelago, Japan (Mori et al., 1999).

Recently, we found a population on another island, Okinawa Island, where predation on sea turtles frequently occurs. We conducted a four-year field survey of foraging behaviours on sea turtles by $L$. semicarinatus at our study site and found a foraging strategy different from the previous observations on islands in Kerama Group (Mori et al., 1999). In this paper, based on a comparison of foraging strategies between the populations on different islands, we discuss the relationship between environmental factors and the switching of snake foraging tactics. Furthermore, we had an opportunity to record the time spent by snakes within patches quantitatively based on the fixed-point video cameras and test the GUT rule under natural conditions. Additionally, we describe two unique feeding behaviours of the snake, burrowing tunnels and taking away food, and discuss the ecological role and consequences of these behaviours in relation to the foraging strategy of L. semicarinatus that has evolved in a local population on Okinawa Island.

\section{Methods}

\subsection{Subjects}

Lycodon semicarinatus is endemic to Japan and is a colubrid snake distributed on islands in the central part of the Ryukyu Archipelago. This snake shows a sexual size dimorphism with males being larger than females: the maximum snout-to-vent length (SVL) of males is over $1500 \mathrm{~mm}$, whereas SVL of females rarely exceeds $1000 \mathrm{~mm}$ (Mori et al., 1999; Takiguchi \& Ota, 2006). This snake is considered a nocturnal dietary generalist, preying on almost all types of vertebrates, such as freshwater fish, frogs, lizards, snakes (including cannibalism), small birds, and small mammals (Mori \& Moriguchi, 1988; Hamanaka et al., 2014). On Okinawa Island and several islands of the Kerama Group, coastal populations of L. semicarinatus have been reported to prey on hatchlings and eggs of green sea turtles, Chelonia mydas, and loggerhead sea turtles, Caretta caretta (Mori et al., 1999; Matsumoto \& Takaoka, 2013; Matsumoto, 2017). This snake utilises both foraging tactics alternately when it forages on sea turtles on the Kerama 
islands (mainly Yakabi and Kuba Islands, of which areas are $1.29 \mathrm{~km}^{2}$ and $1.57 \mathrm{~km}^{2}$, respectively).

In the central part of the Ryukyu Archipelago, many individuals of $\mathrm{Ca}$. caretta and Ch. mydas lay eggs on sandy beaches from April to September. Clutch size of Ca. caretta and Ch. mydas is $112.9 \pm 9.3$ and $108 \pm$ 18.8 , respectively (mean $\pm \mathrm{SD}$; van Buskirk \& Crowder, 1994). The depth from the beach surface to the top of the egg chamber of $\mathrm{Ca}$. caretta and Ch. mydas in the sand is $31.6 \pm 7.9 \mathrm{~cm}$ and $33.2 \pm 11.1 \mathrm{~cm}$, respectively (Hays et al., 1993; Matsuzawa et al., 1995). In general, the incubation-toemergence period of the eggs is approximately two months. Although this period depends on the temperatures inside the egg chamber, the period of most nests of $C a$. caretta range from 46 to 82 days under natural conditions (Matsuzawa et al., 2002).

\subsection{Study site}

Okinawa Island is one of approximately 30 islands composing the central part of the Ryukyu Archipelago. The area of this island is $1207 \mathrm{~km}^{2}$. On the northeastern coast of this island, there are approximately 20 sandy beaches, which are the main nesting sites of Ch. mydas and Ca. caretta in the central Ryukyu Archipelago (Kikukawa et al., 1998). We conducted a field survey on one of these sandy beaches $\left(26.84707^{\circ} \mathrm{N}, 128.28537^{\circ} \mathrm{E}\right)$. The shoreline length of the beach was $816 \mathrm{~m}$, and the mean distance from shoreline to the bush line was $21 \mathrm{~m}$. The bush line was dominated by seaside plants, such as Pandanus odoratissims, Ipomoea pes-caprae and Cirsium brevicaule. The seaside of the coast was surrounded by coral reefs, and the distance from the shoreline to the reef edge line was approximately $400 \mathrm{~m}$. The main components of the beach consist of bioclastic sand, such as coral fragments, shell fragments and foraminifera.

\subsection{Sea turtle nesting survey}

From April to September in 2014, 2016, 2017 and 2018 we walked the beach to find new nests of sea turtles. The sea turtle nesting survey was conducted basically every day with the help of an assistant. When a new nesting trace was found, we examined the presence of fresh eggs by carefully digging a narrow hole in the nest. When eggs were confirmed, we picked out five eggs from the egg chamber to measure the diameter of the eggs. After this process, the eggs and the hole were immediately backfilled. Sea turtle species 
of the nest were identified by the crawling trace that remained on the beach and the diameter of eggs (Bustard, 1972; van Buskirk \& Crowder, 1994). A stick marked with the data (nesting date and species) was inserted into the sand $1 \mathrm{~m}$ from the nest, and four stones were placed to configure a $1 \mathrm{~m}$ square around the nest. Generally, a shallow pit appears on the sand surface above the nest within 7 to 8 days before the hatchling emergence (Kraemer \& Richardson, 1979), and we checked for such signs every day before sunset. In addition, we set night-vision video cameras (Sony FDRAX100, 30 frames/s full HD, infrared night capability) on pre-emergent nests to confirm the exact emerging date of the first and final hatchlings (in general, hatchlings in a nest emerge in several groups over several days; Witherington et al., 1990). Based on the nesting date, hatchling emerging date, and the estimation of the developmental stage of sea turtle nests (Christens, 1990; Godfrey \& Mrosovsky, 1997), each nest was categorized into one of the four stages: pre-hatching (stage I), hatchling pre-emerging (stage II), emerging (stage III), and hatchling post-emerging (stage IV). Furthermore, stage I was categorized into stage I-a (the period from oviposition to 9 days) and stage $\mathrm{I}-\mathrm{b}$ (the period from 10 days to hatching) as needed.

\subsection{Route census}

From April to September in 2014, 2016, 2017 and 2018 we walked the survey area to look for snakes on the beach every hour from around sunset to before sunrise. When we found a snake crawling on the beach, we directly observed the snake from a short distance (from 3 to $5 \mathrm{~m}$ ) with a LED light (80 lumen) because $L$. semicarinatus is considered to be not easily disturbed by an observer (Mori et al., 1999). If the snake started searching or foraging behaviour on a sea turtle nest, we occasionally recorded its behaviour with the night-vision video camera. In this study, 'ambushing' was defined as a snake coiling above a nest and maintaining the posture continuously for more than 1 minute, based on the observations of Mori et al. (1999). Other foraging behaviours were defined as 'active searching.' When the snake began to crawl into the bush, we immediately caught it by hand. If the snake seemed to have recently eaten some food, we occasionally examined its stomach contents by palpation and forced-regurgitation. The examination of stomach contents was not conducted on all individuals to reduce the disturbance due to this operation on snakes. Furthermore, although they seemed to have fed on multiple hatchlings of sea turtles, we confirmed only one hatchling by 
forced-regurgitation. If the snake had burrowed a hole in the nest, we carefully dug up the narrow hole and measured the vertical distance from the beach surface to the deepest point of the hole by using a tape measure.

Before releasing the snake at the capture site, we measured its body size (SVL), sexed, and inserted a PIT tag under its dorsal body skin for permanent individual identification. In addition, a reflective tape was wrapped around the tail of the snake to visually identify the individual from videos recorded by the infrared video camera (see below). The handmade reflective tape (weight under $2 \mathrm{~g}$; width $2 \mathrm{~cm}$ ) with a different light-reflecting pattern covered the skin $5 \mathrm{~cm}$ from the tail tip. The marking tape was shed spontaneously in a relatively short period (up to 2 months) or dropped with the moulted skin of the snake.

\subsection{Data collection by fixed videography}

From April to September in 2016, 2017 and 2018 we set the night-vision video cameras on the marked nests to record foraging behaviour of any L. semicarinatus that may come close to the nests. Each camera started recording before sunset and recorded a video for approximately eight hours continuously. The cameras were set 570 times in total. Based on the video data, we analysed behaviours of snakes for each foraging bout (one visit to the nest by a snake). A staying duration was defined as a time from when the snake entered the area within a radius of $1.5 \mathrm{~m}$ from the centre of the nest to when it left the area. The staying duration was measured to the nearest 0.5 minutes. Data in which interactions between individuals affected the staying time were excluded from the analysis. The staying duration was divided into the following three actions: 'exploring' in which the snake made repeated tongue-flicks toward the surface of the beach, 'swallowing' in which the snake ingested a hatchling above the nest after captured it in the sand, and 'burrowing' in which the snake poked its head into the sand. We defined the total time when the head of snakes was hiding in the sand as the burrowing duration because we were not able to distinguish the snakes staying in an already existing tunnel from those digging a new hole, by watching the video data. The duration of each action was measured to the nearest 1 second. The burrowing ratio by a snake per minute was calculated based on the above durations (total burrowing duration/staying duration).

If the video showed a snake that had not been marked with the reflective tape, SVL of the snake was estimated based on the width of the stones placed 
on the nest. All recorded snakes were divided into three size categories: size $\mathrm{S}$ (with SVL $<1000 \mathrm{~mm}$ ), size M (with SVL $>1000 \mathrm{~mm}$ but $<1300 \mathrm{~mm}$ ), and size L (with SVL $>1300 \mathrm{~mm}$ ). The reason for setting the first boundary of $1000 \mathrm{~mm}$ was that most females do not exceed $1000 \mathrm{~mm}$. The other boundary was $1300 \mathrm{~mm}$, which is the median value between $1000 \mathrm{~mm}$ and $1600 \mathrm{~mm}$ (the maximum SVL in this study site).

\subsection{Measurement of characteristics of sandy beach}

During July 2018 sands from beaches on Okinawa and Yakabi Islands were collected for analysis. Sands were sampled at a $25 \mathrm{~m}$ interval along the beach. Each sampling was taken at the midpoint between the shoreline and the bushline. At each sample point, $500 \mathrm{~g}$ of sands were taken from the surface of the beach to measure mean particle diameter. The distribution of particle size was determined by sorting the sands with sieves (mesh sizes were 0.04 , $0.075,0.3,0.5,0.71,2,5,8,10$ and $16 \mathrm{~mm}$ ). The mean particle diameter of sands at each point was calculated by the distribution data and a special formula (following Folk, 1966).

As another physical property of the beach, a 'sand softness' was measured by the specially designed bar and process (a method for evaluating the sand softness by the depth of the bar stuck into the sand; following Kikukawa et al., 1999). The process was taken 5 times at each of the points set at a $25 \mathrm{~m}$ interval along the beach. The length of the bar stuck into the sand was measured to the nearest $1 \mathrm{~mm}$. Each measurement was taken at the midpoint between the shoreline and the bushline.

\subsection{Data analysis}

Data on foraging behaviours of snakes were pooled because not all snakes recorded by fixed videography were able to be identified (see Section 3.3 for detail). The staying duration and burrowing ratio were compared among stages of nests. These two variables were compared also among size classes of snakes and among months when the data was recorded. When the behavioural data were compared among months, the data in May and June were excluded from the analysis due to the small sample size.

We assessed group differences by Fisher's exact test, Student $t$-test, Mann-Whitney $U$-test, and Kruskal-Wallis test followed by pairwise comparisons using Mann-Whitney $U$-test (with Holm's $p$-value adjustment method). In all tests, $p<0.01$ was considered statistically significant. The 
computer software, RStudio (R version 3.5.1 (2018), The R Project for Statistical Computing), was used for the data analysis.

\section{Results}

\subsection{Sea turtle nesting survey}

The total number of clutches laid were $106($ Ca. caretta $=101 ;$ Ch. mydas $=$ 5), 69 (Ca. caretta $=38 ;$ Ch. mydas $=31), 72($ Ca caretta $=61 ;$ Ch. mydas $=11)$ and $36($ Ca. caretta $=28 ;$ Ch. mydas $=8)$ in 2014, 2016, 2017 and 2018, respectively. Although the total number of clutches varied year to year, $C a$. caretta was always dominant in the number of nests over Ch. mydas. Each year, the number of clutches before the emergence of hatchlings gradually increased from late April, reached a maximum in July, and gradually decreased from August to September (Figure 1). The nests tended to be distributed irregularly along the bush line on the beach.

\subsection{Route census}

A total of 72 individual L. semicarinatus (male $=60$; female $=12$ ) were caught during the route census (Figure 2). Most snakes were large males, but several females and small males were also observed on the beach. SVL of

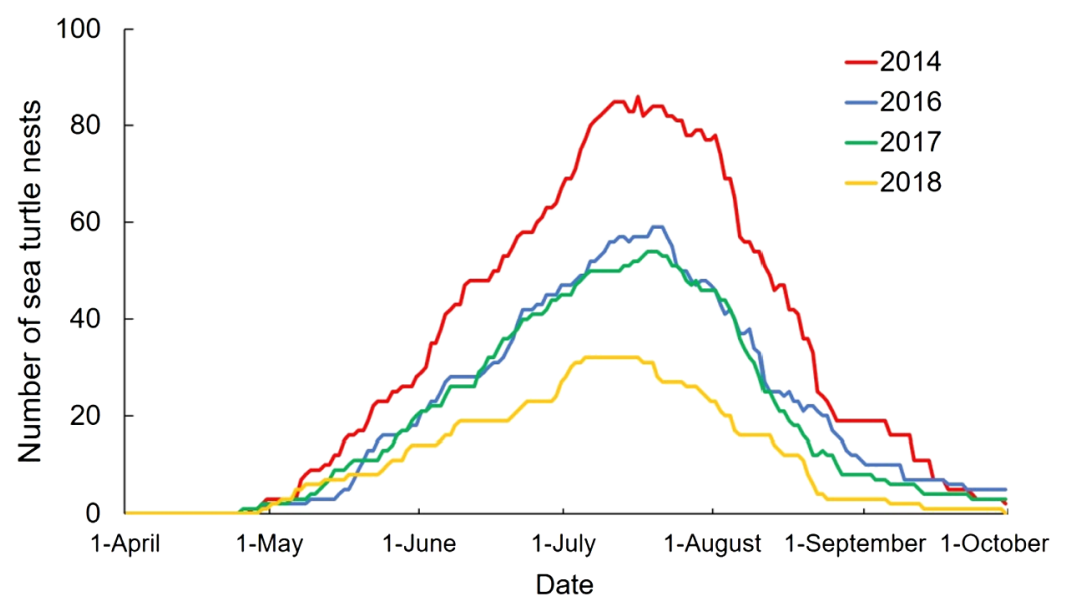

Figure 1. Seasonal change of the number of sea turtle nests on the sandy beach. The solid lines show the total number of nests of Caretta caretta and Chelonia mydas. For the total number the three stages of pre-hatching, hatchling pre-emerging, and emerging were combined. 


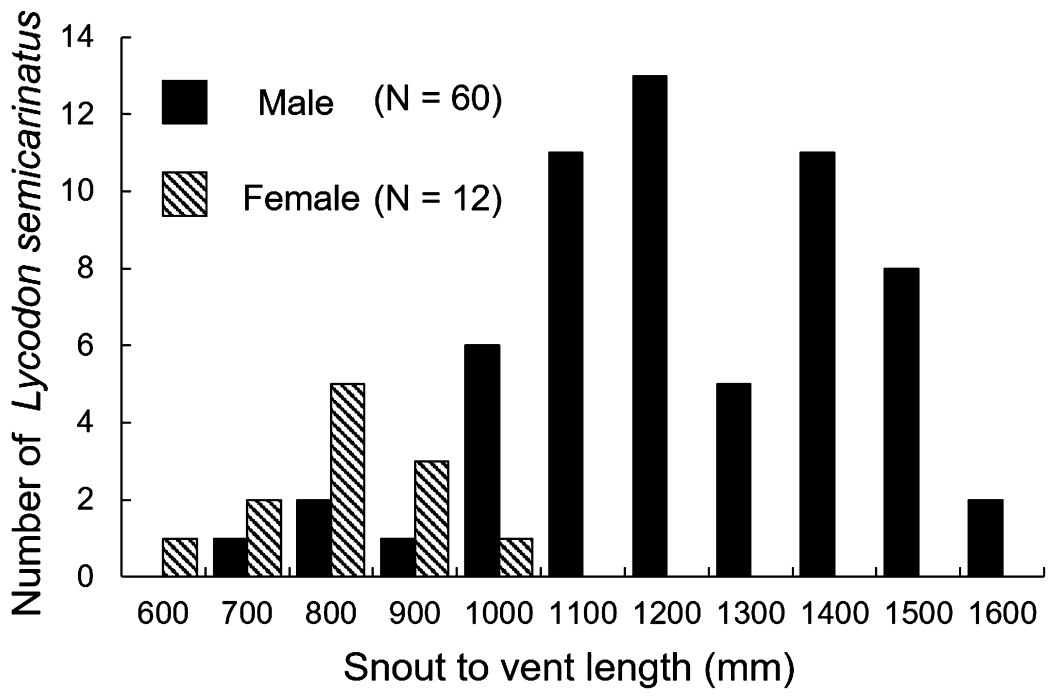

Figure 2. Frequency showing distribution of snout to vent length in males and females of Lycodon semicarinatus collected in the study area.

males was $1281.6 \pm 205.5 \mathrm{~mm}($ mean $\pm \mathrm{SD}$, range $=720-1610, N=60)$ and that of females was $853.5 \pm 96.1 \mathrm{~mm}($ range $=665-1020, N=12)$. During the study period, each snake was captured $2.54 \pm 1.94$ times (mean \pm $\mathrm{SD}$, range $=1-10, N=72$ ). We conducted a total of 183 direct observations of them. All behaviours observed during the route census were classified as 'active searching', and snakes that were ambushing sea turtle hatchlings on nests were never observed.

The active searching by L. semicarinatus was divided into two categories in terms of its spatial scale: 'extensive searching' in a wide-area on the entire beach and 'intensive searching' in a narrow-area centred on sea turtle nests. In the extensive searching, snakes crawled around the entire area of the beach with frequent tongue-flicking. We directly observed five large snakes that were foraging on hatchlings of sea turtles in an area other than nests. When these snakes $(\mathrm{SVL}=1345.2 \pm 130.1 \mathrm{~mm}$, range $=1220-1542$, $N=5$ ) found sea turtle hatchlings crawling to the sea, the snakes grabbed the hatchlings by their jaws and immediately swallowed them in that place. We conducted the examination of stomach contents for snakes that performed extensive searching 120 times; hatchlings were confirmed from the stomach contents of 7 individuals $(\mathrm{SVL}=1363.9 \pm 143.4 \mathrm{~mm}$, range $=$ $1205-1585, N=7)$. No hatchlings were confirmed from the stomach con- 

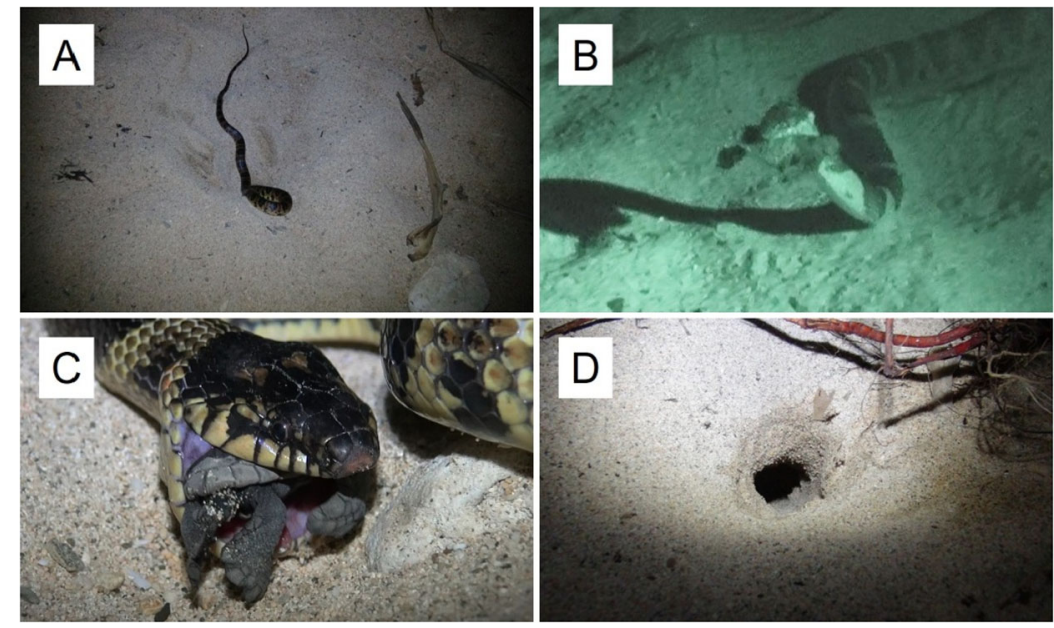

Figure 3. Lycodon semicarinatus foraging on eggs and hatchlings of sea turtles on the sandy beach. (A) A snake burrowing on a nest of Caretta caretta and feeding on the eggs. (B) A snake bringing a hatchling of $\mathrm{Ca}$. caretta away from the nest to the bush area. (C) A snake swallowing a hatchling of $\mathrm{Ca}$. caretta on the nest. See the injured snout of the snake due to burrowing into the sand. (D) A tunnel made by burrowing action of a large snake.

tents of snakes with SVL less than $1200 \mathrm{~mm}$. Besides sea turtles, four species of terrestrial vertebrates (lizards, three Plestiodon marginatus and one Diploderma polygonatum polygonatum; snake, one Cyclophiops semicarinatus and one Ovophis okinavensis) were confirmed from the stomach contents of the snakes on the beach.

When snakes arrived above the nest of sea turtles, they switched to intensive searching in a narrow-area with a radius of approximately $1.5 \mathrm{~m}$ around the nest. Snakes usually began to poke their snout into the sand and burrowed by pushing the sand with their head (Figure 3A). The depth of holes depended on the body size of the snakes (SVL vs. depth, $r=0.74, p<0.01$; Figure 4). Large snakes with SVL more than $1200 \mathrm{~mm}$ were able to burrow deep into the nest, whereas the burrowing ability of small snakes was considerably lower. Large snakes invaded the inside of the egg chamber and preyed on pre-hatched eggs, pre-emergent hatchlings, unhatched eggs, and carcasses of hatchlings.

The feeding method on sea turtles by snakes was different between eggs and hatchlings. We observed snakes feeding on eggs three times. When feeding on eggs in the nest (stage I), the snakes always swallowed the eggs in the sand, and only their posterior body was exposed to the sand during feeding 


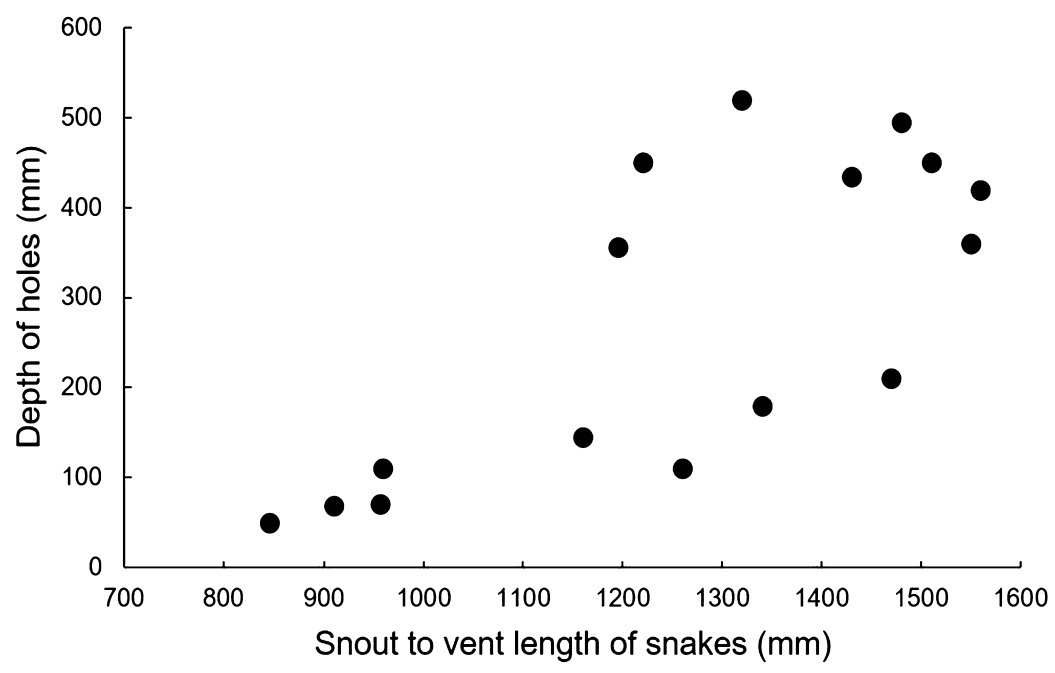

Figure 4. Relationship between body size and burrowing ability of Lycodon semicarinatus. Each plot shows the depth of a tunnel made by a snake $(N=16)$. If a snake burrowed several tunnels on nests during our observation, the deepest value of the tunnels is shown.

(Figure 5A-a). They never pulled eggs out onto the sandy ground by holding an egg with their jaws. After swallowing one or a few eggs in the sand, the snakes pulled their head out from the nest, widely opened their mouth several times, and rubbed their snout on the surface of the beach. Subsequently, the snakes re-entered the nest and fed on other eggs. Three, two, and four eggs (eggshell, egg-yolk and -white) were recovered from undigested stomach contents of the snakes with SVL of $1220 \mathrm{~mm}, 1430 \mathrm{~mm}$ and $1480 \mathrm{~mm}$, respectively. Observations of snakes feeding on hatchlings were made three times. When feeding on a hatchling on the nest (stages II and IV), the snakes pulled the hatchling out from the nest to the sandy ground by holding it with its jaws before swallowing it (Figure 5B). The snakes either immediately swallowed the hatchling above the nest (Figure 5B-a) or brought the hatchling away into the bush area before swallowing it (Figure 5B-b). The snakes with SVL of $1220 \mathrm{~mm}, 1255 \mathrm{~mm}$ and $1390 \mathrm{~mm}$, succeeded in capturing two, one, and one hatchlings in the nest, respectively, and they immediately swallowed the hatchlings above the nest. Subsequently, the three snakes captured an additional hatchling in the nest, and they immediately left the nest for the bush area while grasping the hatchling with its jaws (Figure 3B). After feeding on sea turtles in the sand, their snouts seemed to be damaged due to the intensive burrowing efforts into the sand. In particular, the snout of the snake 


\section{A-a}
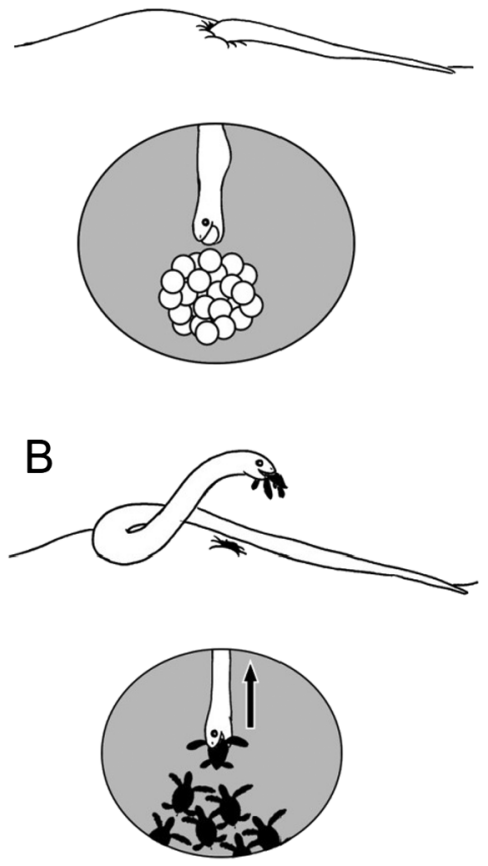

A-b
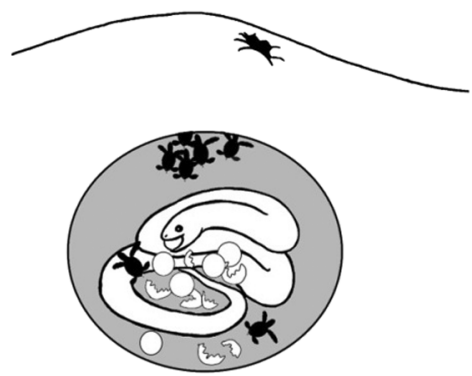

B-a
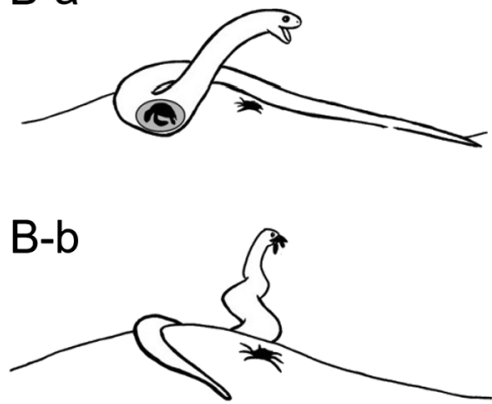

Figure 5. Feeding patterns of Lycodon semicarinatus on eggs and hatchlings of sea turtles. (A-a) a snake exposing its posterior body on the sand and swallowing eggs in the sand. (Ab) a snake burying its whole body into the nest and swallowing eggs and hatchlings in the sand. (B) a snake pulling a hatchling from the nest onto the sand. (B-a) a snake swallowing a hatchling above the nest. (B-b) a snake leaving the nest while grasping a hatchling with its jaw.

with SVL of $1220 \mathrm{~mm}$ was considerably injured, and a little blood oozed out from its tip (Figure 3C).

The hole, which was made by a burrowing manoeuvre of large snakes, remained as a tunnel from the surface of the beach to the egg chamber for one to five days (Figure 3D). The inside surface of the tunnel was smooth due to the behaviour of the snake pushing aside fine sand with its snout. The tunnel was repeatedly used by the same snake that constructed it or used by other snakes to feed on eggs and hatchlings in the nest. In particular, a small snake (SVL: $845 \mathrm{~mm}$, female), which has a low ability to burrow (see Figure 4), succeeded in feeding on eggs by using the tunnel. When this small snake fed on the eggs in the nest, we confirmed that the snake had torn the eggshell and eaten only the contents of the eggs. 
In addition to the nests containing eggs and hatchlings, there were always numerous crawling traces of landed adult sea turtles and ten to thirty bodypits made by adult sea turtles without laying eggs. Snakes sometimes intensively searched on the fresh traces and body-pits and dug shallow holes. However, within approximately 5 minutes of intensive searching, the snakes switched to extensive searching and left the place without eating any prey.

\subsection{Fixed videography}

Fixed night-vision video cameras recorded 373 foraging bouts of snakes on the nests. Most of the snakes were large individuals with SVL more than $1000 \mathrm{~mm}(\mathrm{~S}=16, \mathrm{M}=177, \mathrm{~L}=180)$. Of them $23.3 \%$ were identified individuals based on the marking tape (87/373). The number of times the same individual was recorded was $3.5 \pm 4.0$ times (mean $\pm \mathrm{SD}$, range $=$ $1-15, N=87$ ). Among the individuals marked by the route census, at least $34 \%$ were recorded in videography (25/72). All foraging modes of the snakes were classified as intensive 'active searching', and no ambushing was recorded. In 252 foraging bouts (67.6\%), the snakes exhibited burrowing behaviour.

\subsubsection{Cases of successful hunting}

We determined whether snakes succeeded in hunting sea turtles on the nests from the video data. In the case of foraging on eggs in the sand, it was determined based on the action of opening their mouths observed in route census. The foraging success rate (the number of foraging bouts succeeded in hunting eggs or hatchlings / the number of foraging bouts on the nests) was calculated: an overall success rate was $11.8 \%$ (44/373). The success rate in nest stages I, II, III and IV was 5.1\% (6/118), 20.9\% (19/91), 14.7\% (11/75) and 9\% (8/89), respectively. Approximately half of the successful hunting was the case of using the tunnels already made by large snakes (21/44). If these cases were excluded (the case of reusing a self-made tunnel that existed before coming to the nest was also excluded), the foraging success rate in nest stages I, II, III and IV was $2.6 \%$ (3/115), $11.1 \%$ (9/81), $11.3 \%$ $(8 / 71)$ and $4.7 \%$ (4/85), respectively. These foraging success rates without using pre-made tunnels were significantly different among the nest stages (Fisher's exact test, $p=0.0035$ ).

Snakes that reached the inside of egg chambers always swallowed the eggs with their head in the nest (stage I). When foraging on eggs with their posterior body on the sand, the snakes pulled their heads out from the sand 
every time they finished swallowing several eggs in the nest $(N=7$, Figure 5A-a; see Section 3.2). The staying duration when foraging on eggs was $99.8 \pm 51.4$ minutes (mean $\pm \mathrm{SD}$, range $=40.5-186, N=6$ ). On several occasions, snakes buried their whole body into the sand and stayed in the nest for a while ( stage $\mathrm{I}=1$ case, stage $\mathrm{II}=10$, stage $\mathrm{III}=2$, stage $\mathrm{IV}=7$; Figure 5A-b). Once the snakes hid in the sand, we were not able to observe the snakes again because they stayed in the sand beyond the recording duration of the fixed video cameras. In these cases, although the staying duration of the snakes was not determined, the snakes that entirely hidden in the nests for more than one hour were considered to have succeeded in their foraging on pre-hatched eggs, unhatched eggs, live hatchlings, or dead hatchlings because $L$. semicarinatus has been suggested to remain in the nest of sea turtles for foraging on eggs (Matsumoto \& Takaoka, 2013). One snake (size L) remained in the nest at least for 280 minutes since its tail was hidden in the sand.

Twenty-four sequences of feeding behaviours of snakes on hatchlings were recorded on the nests (stages II, III and IV). Each time the snakes captured a hatchling in the nests, they pulled it out onto the sandy ground. Similar to the results of direct observations, the snakes ate hatchlings in two different ways: immediately swallowing the hatchlings above the nests (Figure 5B-a) and bringing the hatchlings away into the bush area (Figure 5B-b; the taking-away behaviour can be seen in the videos that can be accessed at 10.6084/m9.figshare.14706132). Furthermore, there were four patterns of feeding on hatchlings in one visit of snakes: (1) swallowed only one hatchling above the nest, (2) took-away only one hatchling, (3) swallowed multiple hatchlings above the nest, and (4) after swallowed one or multiple hatchlings, took-away one hatchling. The taking-away behaviour accounted for $70.8 \%$ of the cases in which the snake pulled the hatchling out from the nest (17/24). The frequency that these snakes returned to the same nest at the same night was at least $52.9 \%$ (9/17). The returned snakes resumed foraging on other hatchlings in the nest. In particular, one snake (SVL: $1425 \mathrm{~mm}$ ) exhibited at least four round-trips between the nest and the bush area within 120 minutes to forage on a total of six hatchlings: on its first visit to the nest, the snake swallowed the first hatchling and took the second one away; on its second visit, it captured the third one and took it away; on its third visit, it swallowed the fourth one and took the fifth one away; and on its fourth visit, it captured the sixth one and took it away. 
The number of hatchlings captured by a snake per foraging bout was $1.3 \pm 0.6$ (mean $\pm \mathrm{SD}$, range $=1-3, N=24$ ). In the cases of swallowing hatchlings above nests, the snakes tended to swallow hatchlings from its head (head-first ingestion $=10$, tail-first ingestion $=2$, unknown $=3$ ), and the swallowing duration was $5.6 \pm 3.5$ minutes (mean $\pm \mathrm{SD}$, range $=2-11.5$, $N=15)$.

\subsubsection{Cases of unsuccessful hunting}

Although all snakes actively performed intensive searching above and in the nests of sea turtles, many snakes left the nests without successfully eating food. In the cases of unsuccessful search, the overall staying duration was $5.5 \pm 10.7$ minutes (median $\pm \mathrm{SD}$, range $=0.5-83, N=269$ ). There was no significant difference in the staying duration among the stages of nests (Kruskal-Wallis test, $\chi^{2}=2.99$, df $=3, p=0.39$, Figure 6): the staying duration in stage I-a, I-b, II, III and IV was $5.0 \pm 5.5$ minutes $(N=6), 6.0 \pm$

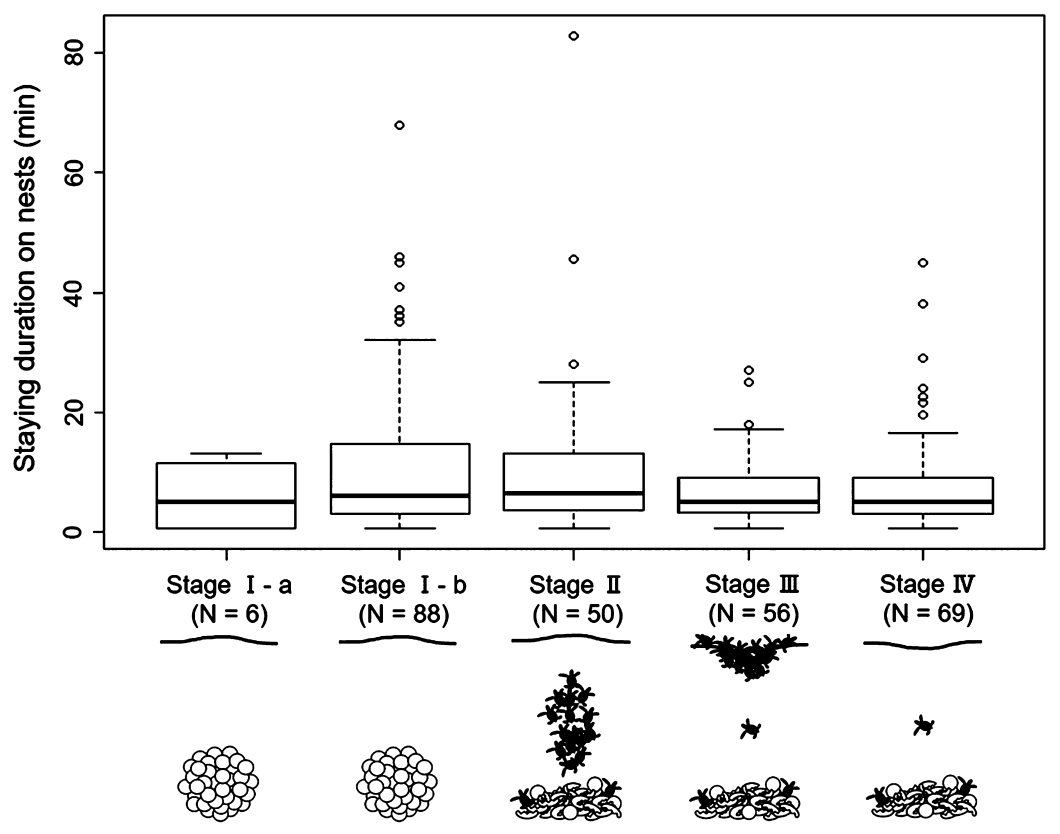

Figure 6. Relationship between staying duration of snakes and stage of nests. The boxplot shows the staying duration of Lycodon semicarinatus when hunting on nests was unsuccessful. See text for the detailed definition of each stage of nests. Indicated by the boxplot the median (centre bar), the 25 and 75 percent quartiles (box ends), the 5 and 95 percent quartiles (small horizontal bars), and outliers (circles). 


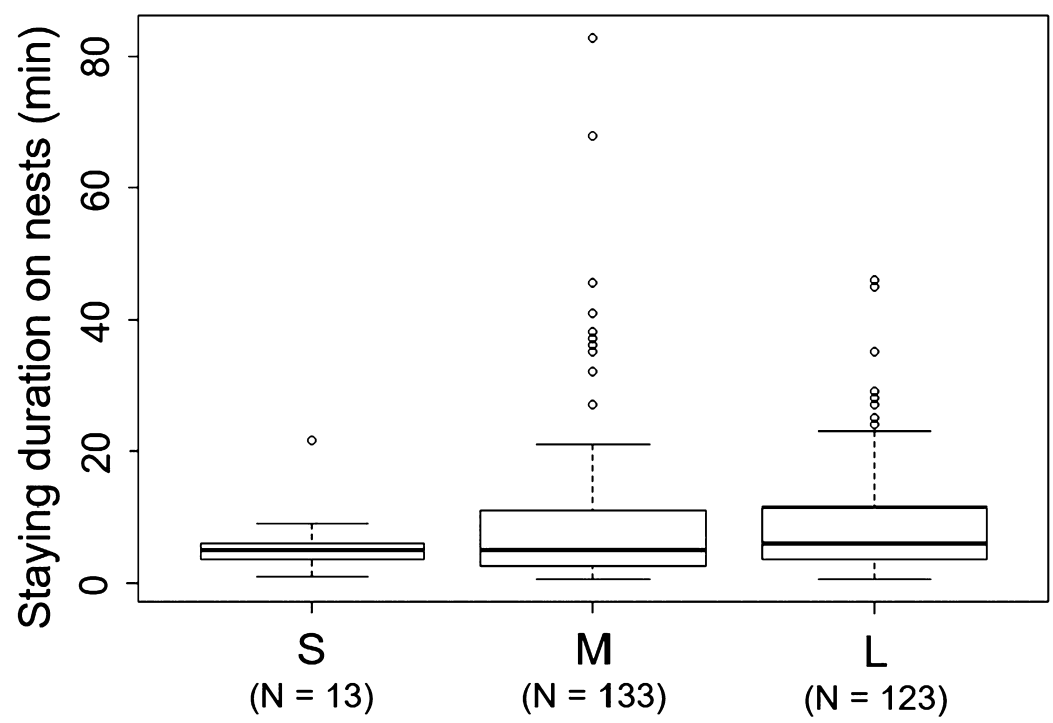

Figure 7. Relationship between staying duration and snout to vent length of snakes. The boxplot shows the staying duration of Lycodon semicarinatus when hunting on nests was unsuccessful. See text for the detailed definition of each size of snakes. Indicated by the boxplot the median (centre bar), the 25 and 75 percent quartiles (box ends), the 5 and 95 percent quartiles (small horizontal bars), and outliers (circles).

12.9 minutes $(N=88), 6.5 \pm 13.4$ minutes $(N=50), 5.0 \pm 5.7$ minutes $(N=56)$ and $5.0 \pm 8.3$ minutes $(N=69)$, respectively. There was also no significant difference in the staying duration among the size classes of snakes (Kruskal-Wallis test, $\chi^{2}=2.56, \mathrm{df}=2, p=0.28$, Figure 7): the staying duration in $\mathrm{S}, \mathrm{M}$ and $\mathrm{L}$ was $5.0 \pm 5.2$ minutes $(N=13), 5.0 \pm 12.3$ minutes $(N=133)$ and $6.0 \pm 9.1$ minutes $(N=123)$, respectively. Furthermore, there was no significant difference in the staying duration among the months when the searching behaviours was recorded (Kruskal-Wallis test, $\chi^{2}=$ $1.16, \mathrm{df}=3, p=0.76$, Figure 8): the staying duration for July, August and September was $5.5 \pm 12.2$ minutes $(N=77), 6.0 \pm 11.3$ minutes $(N=119)$ and $4.8 \pm 7.8$ minutes $(N=66)$, respectively.

There was no significant difference in the burrowing ratio by a snake among the stages of nests (Kruskal-Wallis test, $\chi^{2}=9.14$, $\mathrm{df}=3, p=$ 0.027, Figure 9): the ratios in stages I, II, III and IV were $0.23 \pm 0.22$ (mean $\pm \mathrm{SD} ; N=94), 0.32 \pm 0.22(N=50), 0.21 \pm 0.19(N=56)$ and $0.23 \pm 0.26(N=69)$, respectively. There was also no significant difference in the burrowing ratio among the months when the searching behaviours was 


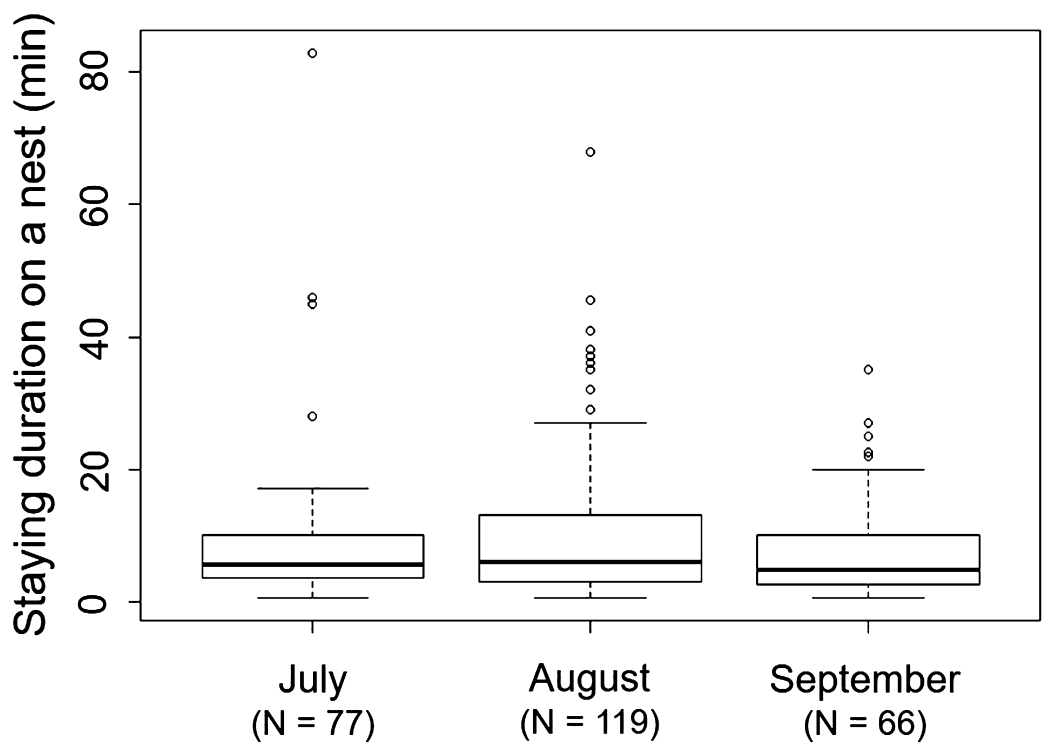

Figure 8. Relationship between staying duration and foraging period. The boxplot shows the staying duration of Lycodon semicarinatus when hunting on nests was unsuccessful. The foraging period was divided by month when the behaviour was recorded. Indicated by the boxplot the median (centre bar), the 25 and 75 percent quartiles (box ends), the 5 and 95 percent quartiles (small horizontal bars), and outliers (circles).

recorded (Kruskal-Wallis test, $\chi^{2}=1.16, \mathrm{df}=3, p=0.76$, Figure 10 ): the ratios for July, August and September were $0.30 \pm 0.22(N=77), 0.23 \pm$ $0.22(N=119)$, and $0.22 \pm 0.22(N=66)$, respectively. On the other hand, there was a significant difference in the burrowing ratios among the size classes of snakes (Kruskal-Wallis test, $\chi^{2}=10.07, \mathrm{df}=2, p=0.0065$, Figure 11): the ratio in $\mathrm{S}, \mathrm{M}$ and $\mathrm{L}$ was $0.14 \pm 0.17(N=13), 0.23 \pm 0.23$ $(N=133)$, and $0.27 \pm 0.22(N=123)$, respectively. While staying on the nest, large snakes spent more time in burrowing than small snakes ( $p$-values of $\mathrm{S}$ vs. $\mathrm{L}, \mathrm{S}$ vs. $\mathrm{M}$ and $\mathrm{M}$ vs. $\mathrm{L}$ were $0.016,0.066$ and 0.079; pairwise comparisons using Mann-Whitney $U$-test with Holm correction).

\subsection{Characteristics of sandy beaches}

The particle diameter of the sand grains on Okinawa and Yakabi Islands was $1.32 \pm 1.57 \mathrm{~mm}(N=33)$ and $6.88 \pm 2.69 \mathrm{~mm}(N=20)$, respectively (mean $\pm \mathrm{SD}$, Wilcoxon rank sum test, $W=38.5, p<0.0001$ ). The sand softness of the beach on Okinawa Island was higher than that on Yakabi Island. The depth of the bar stuck into the sand on Okinawa and Yakabi 


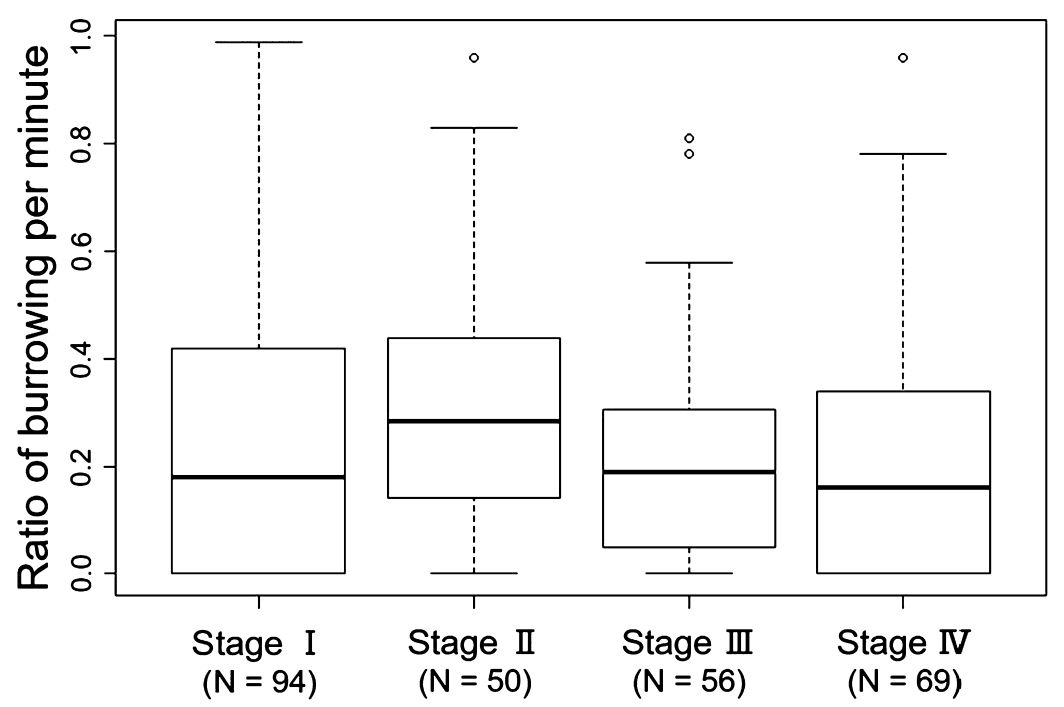

Figure 9. Relationship between burrowing ratio and the stage of nests. The boxplot shows the rate of burrowing duration to the staying duration of Lycodon semicarinatus by stages of nests. See text for the detailed definition of each stage. Indicated by the boxplot the median (centre bar), the 25 and 75 percent quartiles (box ends), the 5 and 95 percent quartiles (small horizontal bars), and outliers (circles).

Islands was $396 \pm 97 \mathrm{~mm}(N=33)$ and $235 \pm 107 \mathrm{~mm}(N=20)$, respectively (Student's $t$-test, $t=5.65, \mathrm{df}=51, p<0.0001$ ).

\section{Discussion}

In this study, we found three main behavioural features of Lycodon semicarinatus: (1) the snake employed only active searching to forage on sea turtles on Okinawa Island; (2) snakes that failed to obtain prey always left the nest after a similar staying duration; and (3) when the snake captured a hatchling in the nest, they often brought away the hatchling into the nearby bush area before swallowing it.

\subsection{Plasticity of foraging strategy}

In general, the predation on sea turtles is not common in snakes. Although a few snakes prey on sea turtles, they forage on either only eggs (Mora \& Robinson, 1984; Huang et al., 2011) or only hatchlings (Hendrickson, 1958; Crother, 1986; Arpayoglou \& Martin, 2011). Lycodon semicarinatus is unique in that it forages on both eggs and hatchlings (Mori et al., 


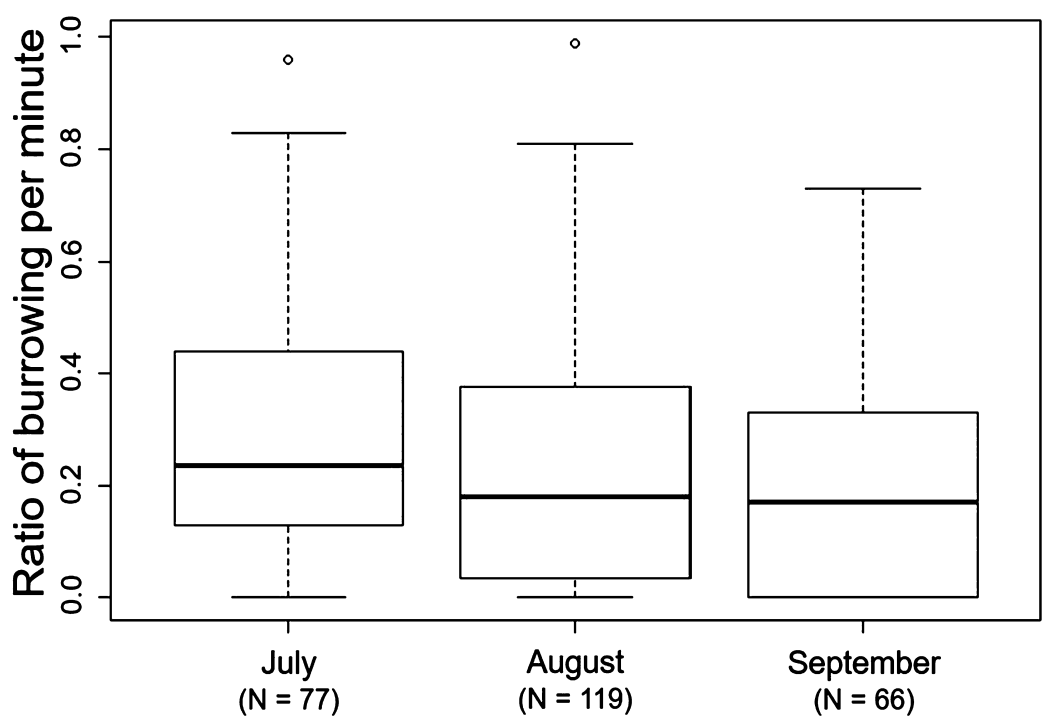

Figure 10. Relationship between burrowing ratio and foraging period. The boxplot shows the burrowing ratio of Lycodon semicarinatus by the month when the behavior was recorded. Indicated by the boxplot the median (centre bar), the 25 and 75 percent quartiles (box ends), the 5 and 95 percent quartiles (small horizontal bars), and outliers (circles).

1999), of which activity levels vary: from completely stationary eggs through restricted moving hatchlings in nests to actively moving hatchlings on the sandy ground. Mori et al. (1999) have suggested that alternative foraging tactics by L. semicarinatus on the Kerama islands is adapted to exploit sea turtles of such various activity levels. Diversity of prey activity levels may be associated with the evolutionary driver of alternative foraging tactics (Balent \& Andreadis, 1998). However, our observations demonstrated that L. semicarinatus on Okinawa island employs a single foraging tactic (active searching) despite the fact that the snake forages on both eggs and hatchlings of sea turtles. Therefore, the diversity of prey activity level does not necessarily drive the evolution of switching of foraging tactics in L. semicarinatus.

There are four possible factors that have led to the different foraging strategy between the two populations. The first possible factor is the density of sea turtle nests in sandy beaches. The density of nests is almost similar between the beaches on the two islands: that on Okinawa and Yakabi Islands is 0.0041 clutches $/ \mathrm{m}^{2}$ (4-year average) and 0.005 clutches $/ \mathrm{m}^{2}$ (Mori et al., 2019), respectively. Therefore, it is unlikely that difference in the nest density causes the different foraging strategy. The second possible factor is predatory 


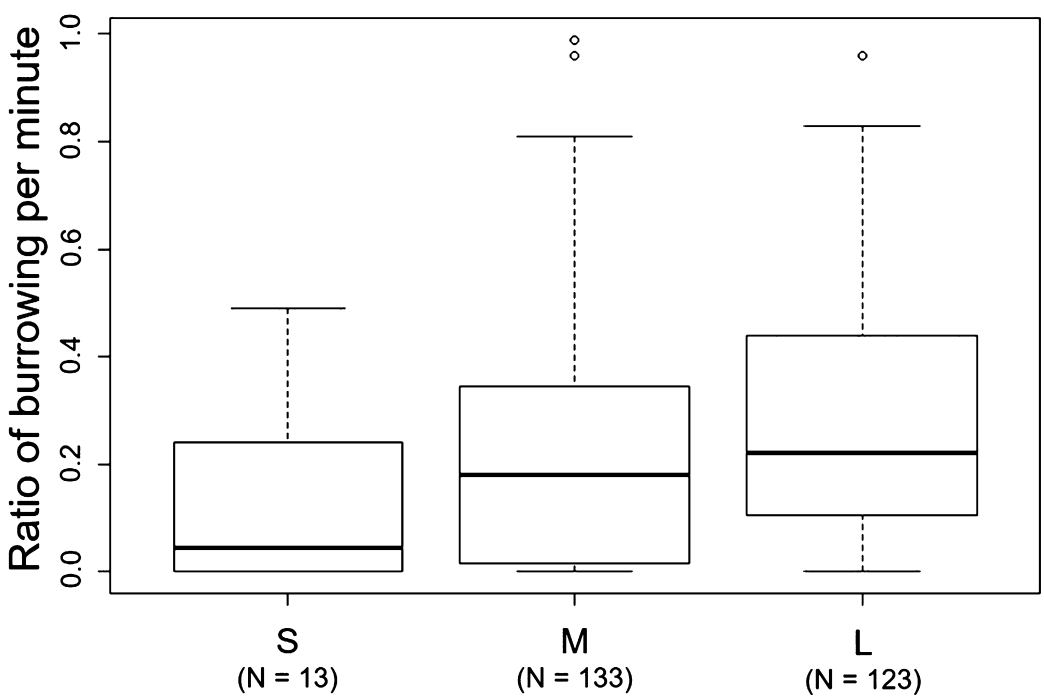

Figure 11. Relationship between burrowing ratio and snout to vent length of snakes. The boxplot shows the burrowing ratio of Lycodon semicarinatus by snout to vent length of snakes. Indicated by the boxplot the median (centre bar), the 25 and 75 percent quartiles (box ends), the 5 and 95 percent quartiles (small horizontal bars), and outliers (circles).

threat. Although several predatory species of juveniles of L. semicarinatus have been reported (Tanaka \& Mori, 2000), there is no predator that is able to prey on large adults of $L$. semicarinatus that forage on sea turtle hatchlings on Okinawa and Yakabi Islands. Therefore, predatory threat is also unlikely to be involved in the difference in the foraging strategy of $L$. semicarinatus.

The third possible factor is the amount of prey animals other than sea turtles. The number of native terrestrial vertebrate species differs between Okinawa and Yakabi Island: for example, the number of native terrestrial reptiles on Okinawa and Yakabi Islands are 21 species and 11 species, respectively (Maenosono \& Toda, 2007). In environments where prey resources other than sea turtles are scarce, sea turtles are more important resources to the survival of dietary generalist snakes. Therefore, on Yakabi Island, if snakes detect the nest where hatchlings are likely to emerge soon (it has been suggested that the snakes are able to perceive the internal state of nests to some extent; Mori et al., 1999), it may be possible to make a great profit for the snakes by spending more time on the nest. In contrast, the benefits of tenacity on one prey may not be so high on Okinawa Island as on Yakabi Island. In fact, prey animals other than sea turtles were confirmed from the stomach 
contents of snakes that appeared on the sandy beach on Okinawa Island, but only sea turtles were confirmed on Yakabi Island (Mori et al., 1999). Consequently, it is considered that the amount of prey other than sea turtles would be associated with the difference in the foraging strategy of L. semicarinatus. Investigation of the actual amount of available prey resources within the home range of the snake is definitely necessary to test this possibility.

The fourth possible factor is the characteristics of sandy beach. The beach on Okinawa Island mainly consisted of fine sand, and the sand softness was relatively high. In contrast, the beach on Yakabi Island consisted of large sandstones and coral stones, and the sand softness was relatively low. This difference in the characteristics of the beaches may affect the degree of difficulty for burrowing and the strength of tunnels made by snakes. On the soft beach on Okinawa Island, large snakes with SVL of more than $1200 \mathrm{~mm}$ are able to burrow into any nest and forage on eggs and hatchlings in the sand. In contrast, snakes may not be able to burrow into several nests formed on the hard beach on Yakabi Island. In fact, we attempted to manually dig a narrow hole in a large gravel-rich nest to confirm the eggs for 37 nests, but we were not able to dig deep enough to reach the egg chambers of 27 nests. We were not able to dig deep because the hole collapsed quickly. The persistence of a tunnel made on sandy beaches changes depending on the water content of the sand that composes the tunnel, and the persistence increases as the water content increases except under saturated conditions (Shinoda et al., 2019). The water content changes depending on the shape and size of the sand: the water content increases as the sand grain size becomes finer (Mitarai \& Nori, 2006). Therefore, it is quite possible that sturdy and durable tunnels are formed on the beach consisted of fine sand grains on Okinawa Island, whereas usable tunnels are not formed on dry and coarse sand beach on Yakabi Island. As a result, snakes on Okinawa Island are able to forage on eggs and hatchlings in the nest by using tunnels made by other snakes. The snakes may prioritize the tactic of active searching for tunnelled nests over the tactic of ambushing hatchlings above intact nests for a long time. In contrast, it is reasonable for snakes to ambush on the nests until hatchlings emerge onto the surface of the hard sandy beach that is usually difficult to burrow.

\subsection{Giving-up behaviour}

On the sandy beach of Okinawa Island, L. semicarinatus always intensively searched on patchily distributed nests of sea turtles. They exhibited a similar 
staying duration (approximately 5 minutes) irrespective of the nest condition, body size, and month. This giving-up behaviour of the snake can be considered a crucial evidence in nature that supports the GUT rule predicted by Krebs et al. (1974).

Although this giving-up behaviour can be adaptive for foraging on sea turtles, we do not presume that the predation on sea turtles is an evolutionary driving factor of this trait because of the following three reasons. The first reason is that the staying duration did not correspond to the foraging success rate on nests. The foraging success rate depended on the stages of nests: it was easier for snakes to forage on stages II and III than on stages I and IV (see Section 3.3.1). We consider that the changes of prey position in the sand influenced the foraging success of snakes. Considering the foraging success rate, it is expected that snakes should spend more search efforts (search time) on more profitable nests (stages II and III) than on stages I and IV. However, the actual staying duration was always approximately 5 minutes, regardless of the stages of nests (Figure 6). The second reason is that the staying duration did not correspond to the body size of snakes. The burrowing ability of snakes depended on their body size: the large snakes were able to burrow deeply enough to feed on eggs and hatchlings in nests, but small snakes were unable to forage on eggs by burrowing in nests (Figure 4). Small snakes are able to eat eggs only by using tunnels made by large snakes. In addition, the ratio of burrowing behaviour per minute was different between large and small snakes: large snakes tended to burrow in nests more frequently than small snakes (Figure 11). Considering the burrowing ability associated with the body size of snakes, it is expected that the larger snakes should spend more time on nests. However, the actual staying duration was always approximately 5 minutes regardless of the body size of snakes (Figure 7). The third reason is that the staying duration did not correspond to the density of sea turtle nests on the beach. The number of nests on the beach that contain potential food changed during the season: the number was highest in July and gradually decreased until October (Figure 1). In other words, the frequency of encountering nests changes through the nesting season of sea turtles. Considering the changes in the density of profitable nests, it is expected that snakes should stick to the nests they found longer in September than in July. However, the actual staying duration was always approximately 5 minutes regardless of the month (Figure 8 ). Therefore, the 
unique foraging ecology of preying on sea turtles does not seem to be an evolutionary driving factor for the giving-up behaviour.

The giving-up behaviour of $L$. semicarinatus may be associated with the compensation for the inherent weakness of chemical cues used to search for prey. In general, predators use various cues of prey such as visual, auditory, and olfactory cues for their hunting. The use of olfactory chemical cues provides the benefits to active searchers. Predators are able to track distant prey by their chemical trails and detect hidden sedentary prey. Many studies have demonstrated advantages of chemical cues in snakes during foraging behaviour (Roth et al., 1999; Clark, 2004). Nonetheless, chemical cues have also inherent disadvantages. One of the disadvantages is that the chemical traces of prey are not always reliable cues to indicate the current presence of the prey. Even if predators detect a place where the strong odour of prey remains, there may be no one because the prey has already left the place: e.g., avian nests immediately after fledglings flew away. No matter how much time the predators spend on the place without prey, they will never obtain an income suitable for their foraging cost. In fact, we observed unrewarded searching behaviours by $L$. semicarinatus on crawling traces of landed adult sea turtles and body-pits without eggs. This type of unprofitable encounter with chemical cues of prey would occur in any prey species other than sea turtles. Therefore, $L$. semicarinatus may have evolved the behaviour to give up a detected prey chemical at a fixed time (5 minutes) as a method to minimize the cost of the unrewarded searching. This giving-up behaviour may function to increase the opportunities of exploring various prey and maximize the total income under a certain food resource condition. Only if the odour of the prey becomes stronger within 5 minutes of searching, which implies the actual presence of nearby prey, snakes may continue the intensive searching in the patch. This may be the reason why some L. semicarinatus spent well over 5 minutes on one nest.

\subsection{Taking-away behaviour}

In L. semicarinatus on Okinawa Island, we observed another unique foraging behaviour: when a snake captured a hatchling of sea turtles on the nest, the snake immediately left the nest for the bush area while grasping the hatchling with its jaws before swallowing it. This 'taking-away behaviour' causes the risk of missing opportunities to obtain additional prey. In fact, we observed a case that a snake that brought a hatchling away from the nest (stage III) 
missed additional feeding opportunities: during 71 minutes, which is the time from when the snake brought one hatchling away into the bush area to when the snake returned to the nest after swallowed it, 14 hatchlings in the nest moved to the sea. There are at least three possible factors that may induce $L$. semicarinatus to exhibit the taking-away behaviour even under the situation in which the snake has a chance to forage on multiple prey animals continuously: artificial disturbance, avoidance of predators, and conspecific interaction.

First, disturbance by the observers may have caused the retreating response of the snake. This could be true in the case of several taking-away behaviours observed during the direct observations. However, the behaviour was also observed very frequently by fixed videography. Because L. semicarinatus does not have infrared-sensitive pit organs, which are well known in boid, pythonid, and crotaline snakes (Goris, 2011), it is unlikely that the infrared rays emitted by the night-vision video camera affected the behaviour of this snake. Thus, the disturbance by our observations would not be the primary reason that induced the taking-away behaviour. The second factor concerns the possibility of an anti-predator reaction. In general, the predation risk increases in open environments such as sandy beaches. Therefore, snakes may hide in a safe place and swallow food. However, as mentioned above, there is no predator that is able to prey on large adult $L$. semicarinatus. Therefore, an anti-predator response would not be the primary reason that induced the taking-away behaviour. Although sometimes we have observed that the predation on sea turtle hatchlings by ghost crabs (Ocypode sp.) on the beach, this crab is unlikely to be a competitor or predator that affects the foraging behaviour of snakes.

The third factor concerns the possibility of conspecific interaction. The nests that have been exploited by one snake temporarily attract many snakes because they are able to reduce foraging costs by using tunnels. Therefore, staying on such nests for a long time increases the possibility of encountering other individuals. It has been reported that the encounter of two male L. semicarinatus causes a conspecific fight (known as 'combat dance') for sea turtles (Mori et al., 2019). In general, males that engage in conspecific aggressive physical interactions to gain access to resources incur obvious energetic costs (Pough, 1983; Riechert, 1988; Haller, 1995; Neat et al., 1998). Furthermore, in conspecific fights of snakes to access reproductively active females during the mating season, losers incur high reproductive costs: in male Agkistrodon 
piscivorus the rapid increase in CORT (plasma lactate and corticosterone) results from losing the conspecific fights, and high levels of CORT are associated with short-term inhibition of reproductive behaviour (Schuett, 1996; Schuett \& Grober, 2000). If foraging activity of L. semicarinatus is also reduced by losing a fight, the cost to the loser is not only that the sea turtles are robbed by the winner but also that the short-term inhibition of its foraging behaviour results in loss of opportunities to forage on other prey resources. Therefore, immediately after snakes capture a hatchling that requires some duration to swallow (see Section 3.3), they may bring away the hatchling from the nest to reduce the possibility of encountering other individuals. We presume that the taking-away behaviour has developed to avoid excessive occurrences of conspecific agonistic interactions. If this interpretation is true, L. semicarinatus may have evolved a unique sociality that has never been reported in snakes. On the other hand, cannibalism may be also involved in the taking-away behaviour. Although large adult males that are able to swallow sea turtle hatchlings are rarely exposed to the risk of predation by cannibalism, small snakes potentially face this risk (Sasai \& Kadota, 2012). Therefore, it is assumed that small snakes actively avoid other conspecific individuals. If snakes maintain the tendency to avoid cannibalism even after they grow to large size, such propensity may be involved in the motivation of the taking-away behaviour.

\subsection{Conclusions}

Lycodon semicarinatus has different foraging strategies among the populations. We consider that the factors that lead to the difference in foraging strategy are a diversity of prey species other than sea turtles and a characteristic of sandy beaches. On the fine-grained sandy beaches on Okinawa Island, the exploitation on the nests by large snakes formed a sturdy tunnel, and many snakes utilised the tunnel to forage on sea turtles. The tunnels may have facilitated the use of active searching by snakes because finding nests with tunnels reduces foraging costs. In addition, the tunnels may reduce the number of nests that are preyed upon by $L$. semicarinatus because the presence of the tunnels attracts other snakes to the specific nests and distracts them from intact nests on the beach. When the snakes failed to find food on nests without tunnels, they left the nests basically in approximately 5 minutes. This fixed-timed staying duration supported the theoretical prediction of the GUT rule. We consider that $L$. semicarinatus has evolved the giving-up 
behaviour to compensate for the inherent disadvantage of chemical cues to search for prey animals. Furthermore, nests with tunnels increase the probability for snakes to come into contact with other individuals because the nests attract many snakes. When the snakes captured a hatchling in the nest, they brought the hatchling away into the bush area without swallowing it above the nest. They seemed to avoid the potential risk of contact with other individuals. In the future, it is necessary to extend the research target to populations on other islands in order to test the hypothesis presented in this paper. Although we did not handle the data of the interactions between individuals of $L$. semicarinatus on the study site because this paper aims to focus on the foraging behaviours of individuals, the interactions must be analyzed in detail to clarify the proximate factors that lead to the peculiar foraging strategy of $L$. semicarinatus.

\section{Acknowledgements}

We would like to thank Muneyuki Kayo of the Sea Turtle Association of Japan for cooperating in the sea turtle nesting survey. We are also thankful to Masako Izawa of Kitakyushu Museum of Natural History and Human History for providing advice for research planning. This study was supported in part by Grant-in-Aid for JSPS Fellows to KM (18J21914).

\section{References}

Akre, B.G. \& Johnson, D.M. (1979). Switching and sigmoid functional response curves by damselfly naiads with alternate prey available. — J. Anim. Ecol. 48: 703-720.

Arpayoglou, I. \& Martin, R.E. (2011). Cheloniidae (Marine turtles). Hatchling predation. Herpetol. Rev. 42: 416-417.

Aubret, F., Tort, M. \& Sarraude, T. (2015). Evolution of alternative foraging tactics driven by water temperature and physiological constraints in an amphibious snake. — Biol. J. Linn. Soc. Lond. 115: 411-422.

Balent, K.L. \& Andreadis, P.T. (1998). The mixed foraging strategy of juvenile northern water snakes. - J. Herpetol. 32: 575-579.

Benhamou, S. (1992). Efficiency of area-concentrated searching behavior in a continuous patchy environment. - J. Theor. Biol. 159: 67-81.

Bilcke, J., Herrel, A. \& Van Damme, R. (2006). Correlated evolution of aquatic prey-capture strategies in European and American Natricine snakes. - Biol. J. Linn. Soc. Lond. 88: 73-83.

Bustard, R. (ed.) (1972). The lives of turtles. — In: Sea turtles: natural history and conservation. Collins, London, p. 49-73. 
Christens, E. (1990). Nest emergence lag in loggerhead sea turtles. — J. Herpetol. 24: 400402.

Clark, R.W. (2004). Timber rattlesnakes (Crotalus horridus) use chemical cues to select ambush sites. - J. Chem. Ecol. 30: 607-617.

Crother, B.I. (1986). Alsophis cantherigerus (Cuban racer). Diet. - Herpetol. Rev. 17: 47.

Folk, R.L. (1966). A review of grain size parameters. — Sedimentology 6: 73-93.

Formanowicz Jr, D.R. \& Bradley, P.J. (1987). Fluctuations in prey density: effects on the foraging tactics of scolopendrid centipedes. - Anim. Behav. 35: 453-461.

Gibb, J.A. (1958). Predation by tits and squirrels on the eucosmid Ernarmonia conicolana (Heyl.). — J. Anim. Ecol. 27: 375-396.

Godfrey, M.H. \& Mrosovsky, N. (1997). Estimating the time between hatchling of sea turtles and their emergence from the nest. - Chelonian Conserv. Biol. 2: 581-585.

Goris, R.C. (2011). Infrared organs of snakes: an integral part of vision. - J. Herpetol. 45: $2-14$.

Green, R.F. (1984). Stopping rules for optimal foragers. - Am. Nat. 123: 30-43.

Green, R.F. (1987). The giving-up-time rule as a strategy for animals foraging systematically in a patchy environment. - Technical Report 87-3. University of Minnesota. Computer Science, Mathematics and Statistics.

Haller, J. (1995). Biochemical background for an analysis of cost-benefit interrelations in aggression. - Neurosci. Biobehav. Rev. 19: 599-604.

Hamanaka, K., Mori, A. \& Moriguchi, H. (2014). Literature survey on food habit of snakes in Japan: revisited. — Bull. Herpetol. Soc. Jpn.: 167-181.

Hays, G.C., Adams, C.R. \& Speakman, J.R. (1993). Reproductive investment by green turtles nesting on Ascension Island. — Can. J. Zool. 71: 1098-1103.

Helfman, G.S. (1990). Mode selection and mode switching in foraging animals. - Adv. Stud. Behav. 19: 249-298.

Hendrickson, J.R. (1958). The green sea turtle, Chelonia mydas (Linn.) in Malaya and Sarawak. — Proc. Zool. Soc. Lond. 130: 455-534.

Horesh, S.J.A., Sivan, J., Rosenstrauch, A., Tesler, I., Degen, A.A. \& Kam, M. (2017). Seasonal biotic and abiotic factors affecting hunting strategy in free-living Sahara sand viper, Cerastes vipera. - Behav. Process. 135: 40-44.

Huang, W.S., Greene, H.W., Chang, T.J. \& Shine, R. (2011). Territorial behavior in Taiwanese kukurisnakes (Oligodon formosanus). — Proc. Natl. Acad. Sci. USA 108: 7455-7459.

Huey, R.B. \& Pianka, E.R. (1981). Ecological consequences of foraging mode. - Ecology 62: 991-999.

Iwasa, Y., Higashi, M. \& Yamamura, N. (1981). Prey distribution as a factor determining the choice of optimal foraging strategy. - Am. Nat. 117: 710-723.

Johnson, D.M. \& Crowley, P.H. (1980). Odonate "hide and seek": habitat specific rules. In: Evolution and ecology of zooplankton communities (Kerfoot, W.C., ed.). University Press of New England, Hanover, NH, p. 569-579.

Kikukawa, A., Kamezaki, N. \& Ota, H. (1998). Current status of the sea turtles nesting on Okinawajima and adjacent islands of the central Ryukyus, Japan. - Biol. Conserv. 87: 149-153. 
Kikukawa, A., Kamezaki, N. \& Ota, H. (1999). Factors affecting nesting beach selection by loggerhead turtles (Caretta caretta): a multiple regression approach. — J. Zool. 249: 447-454.

Kraemer, J.E. \& Richardson, J.I. (1979). Volumetric reduction in nest contents of loggerhead sea turtles (Caretta caretta) (Reptilia, Testudines, Cheloniidae) on the Georgia coast. J. Herpetol. 13: 255-260.

Krebs, J.R. (1973). Behavioral aspects of predation. — In: Perspectives in ethology, vol. 1 (Bateson, P.P.G. \& Klopfer, P.H., eds). Plenum, New York, NY, p. 73-111.

Krebs, J.R., Ryan, J.C. \& Charnov, E.L. (1974). Hunting by expectation or optimal foraging? A study of patch use by chickadees. - Anim. Behav. 22: 953-964.

Maenosono, T. \& Toda, M. (2007). Distributions of amphibians and terrestrial reptiles in Ryukyu Archipelago: a review of published records. - Akamata 18: 28-46.

Matsumoto, K. (2017). Diurnal predation on sea turtle eggs by Dinodon semicarinatum and excessive tick parasites on snakes on Tokashiki Island. - Akamata 27: 29-32.

Matsumoto, K. \& Takaoka, C. (2013). Dinodon semicarinatum found from a sea turtle's nest in the eastern coast of Kunigami Village, Okinawa Prefecture. - Akamata 24: 25-28.

Matsuzawa, Y., Bando, T. \& Sakamoto, W. (1995). Sand temperature and depth of egg chamber of loggerhead sea turtle in Senri-hama coast. - Umigame Newsletter of Japan 26: 3-7.

Matsuzawa, Y., Sato, K., Sakamoto, W. \& Bjorndal, K.A. (2002). Seasonal fluctuations in sand temperature: effects on the incubation period and mortality of loggerhead sea turtle (Caretta caretta) pre-emergent hatchlings in Minabe, Japan. — Mar. Biol. 140: 639-646.

Mattison, C. (1995). The encyclopedia of snakes. — Facts on File, New York, NY.

McLaughlin, R.L. (1989). Search modes of birds and lizards: evidence for alternative movement patterns. - Am. Nat. 133: 654-670.

McNair, J.N. (1982). Optimal giving-up times and the marginal value theorem. - Am. Nat. 119: 511-529.

Mitarai, N. \& Nori, F. (2006). Wet granular materials. - Adv. Phys. 55: 1-45.

Mora, J.M. \& Robinson, D.C. (1984). Predation of sea turtle eggs (Lepidochelys) by the snake Loxocemus bicolor Cope. - Rev. Biol. Trop. 32: 161-162.

Mori, A. \& Moriguchi, H. (1988). Food habits of the snakes in Japan: a critical review. Snake 20: 98-113.

Mori, A., Ota, H. \& Kamezaki, N. (1999). Foraging on sea turtle nesting beaches: flexible foraging tactics by Dinodon semicarinatum (Serpentes: Colubridae). — In: Tropical island herpetofauna: origin, current diversity, and conservation (Ota, H., ed.). Elsevier, Amsterdam, p. 99-128.

Mori, A., Ota, H. \& Hirate, K. (2019). Defending resources on isolated islands: snakes compete for hatchling sea turtles. - In: Islands and snakes: isolation and adaptive evolution (Lillywhite, H.B. \& Martins, M., eds). Oxford University Press, New York, NY, p. 289309.

Mushinsky, H.R. (1987). Foraging ecology. — In: Snakes: ecology and evolutionary biology (Seigel, R.A., Collins, J.T. \& Novak, S.S., eds). Macmillan, New York, NY, p. 302-334. 
Mushinsky, H.R. \& Mullin, S.J. (1995). Foraging ecology of the mangrove salt Marsh snake, Nerodia clarkii compressicauda: effects of vegetational density. - Amphibia-Reptilia 16: 167-175.

Neat, F.C., Taylor, A.C. \& Huntingford, F.A. (1998). Proximate costs of fighting in male cichlid fish: the role of injuries and energy metabolism. - Anim. Behav. 55: 875-882.

Perry, G. (1999). The evolution of search modes: ecological versus phylogenetic perspectives. - Am. Nat. 153: 98-109.

Pianka, E.R. (1966). Convexity, desert lizards, and spatial heterogeneity. - Ecology 47: 1055-1059.

Pietruszka, R.D. (1986). Search tactics of desert lizards: how polarized are they? - Anim. Behav. 34: 1742-1758.

Pope, C.H. (1975). The giant snakes. — Alfred A. Knopf, New York, NY.

Pough, F.H. (1983). Amphibians and reptiles as low-energy systems. - In: Behavioral energetics: the cost of survival in vertebrates (Aspey, W.P. \& Lustick, S.I., eds). Ohio State University Press, Columbus, OH, p. 141-188.

Racey, P.A. \& Swift, S.M. (1985). Feeding ecology of Pipistrellus pipistrellus (Chiroptera: Vespertilionidae) during pregnancy and lactation: I. foraging behaviour. - J. Anim. Ecol. 54: 205-215.

Regal, P.J. (1978). Behavioral differences between reptiles and mammals: an analysis of activity and mental capacities. - In: Behavior and neurology of lizards (Greenberg, N. \& Maclean, P.D., eds). Department of Health, Education, and Welfare, Washington, DC, p. 183-202.

Reinert, H.K., Cundall, D. \& Bushar, L.M. (1984). Foraging behavior of the timber rattlesnake, Crotalus horridus. - Copeia: 976-981.

Riechert, S.E. (1988). The energetic costs of fighting. - Am. Zool. 28: 877-884.

Roth, E.D., May, P.G. \& Farrell, T.M. (1999). Pigmy rattlesnakes use frog-derived chemical cues to select foraging sites. - Copeia: 772-774.

Sasai, T. \& Kadota, Y. (2012). An example of Dinodon semicarinatum eating another Dinodon semicarinatum in Gushikawajima Island. — Akamata 23: 6-8.

Schmitz, O.J. (2010). Resolving ecosystem complexity. — Princeton University Press, Princeton, NJ.

Schoener, T.W. (1971). Theory of feeding strategies. - Annu. Rev. Ecol. Evol. Syst. 2: 369404.

Schuett, G.W. (1996). Fighting dynamics of male copperheads, Agkistrodon contortrix (Serpentes, Viperidae): stress-induced inhibition of sexual behavior in losers. - Zoo Biol. 15: 209-221.

Schuett, G.W. \& Grober, M.S. (2000). Post-fight levels of plasma lactate and corticosterone in male copperheads, Agkistrodon contortrix (Serpentes, Viperidae): differences between winners and losers. - Physiol. Behav. 71: 335-341.

Shine, R. (1980). Ecology of the Australian death adder Acanthophis antarcticus (Elapidae): evidence for convergence with the Viperidae. - Herpetologica 36: 281-289. 
Shinoda, A., Fujiwara, S.-I., Niiya, H. \& Katsuragi, H. (2019). Physical constraints on sand crab burrows: mechanical properties of wet sand explain the size and spatial distributions of burrows on beaches. - PLoS ONE 14: e0215743.

Slip, D.J. \& Shine, R. (1988). Reptilian endothermy: a field study of thermoregulation by brooding diamond pythons. - J. Zool. 216: 367-378.

Stephens, D.W. \& Krebs, J.R. (1986). Foraging theory. — Princeton University Press, Princeton, NJ.

Takiguchi, I. \& Ota, H. (2006). Sexual dimorphism in a colubrid snake, Dinodon semicarinatum (Reptilia: Squamata), Okinawajima Island of the Central Ryukyus, Japan. — Curr. Herpetol. 25: 79-92.

Tanaka, K. \& Mori, A. (2000). Literature survey on predators of snakes in Japan. - Curr. Herpetol. 19: 97-111.

van Buskirk, J. \& Crowder, L.B. (1994). Life-history variation in marine turtles. — Copeia: 66-81.

Vanhooydonck, B., Herrel, A. \& Van Damme, R. (2007). Interactions between habitat use, behavior, and the trophic niche of lacertid lizards. - In: Lizard ecology (Reilly, A.M., McBrayer, L.B. \& Miles, D.B., eds). Cambridge University Press, Cambridge, p. 427450.

Verwaijen, D. \& Van Damme, R. (2007). Does foraging mode mold morphology in lacertid lizards? - J. Evol. Biol. 20: 1950-1961.

Witherington, B.E., Bjorndal, K.A. \& McCabe, C.M. (1990). Temporal pattern of nocturnal emergence of loggerhead turtle hatchlings from natural nests. — Copeia: 1165-1168. 